\title{
NMR Heteronuclear Correlation between Quadrupolar Nuclei in Solids
}

\author{
Dinu luga ${ }^{a}$, Claudia Morais ${ }^{a}$, Zhehong Gan $^{b}$, Daniel R.Neuville ${ }^{c}$, Laurent Cormier ${ }^{d}$, Dominique Massiot ${ }^{a}$ \\ ${ }^{a}$ CRMHT-CNRS, $1 D$ Avenue de la Recherche Scientifique, 45071 Orléans cedex 2, France \\ ${ }^{b}$ National High Magnetic Field Laboratory, 1800 E. Paul Dirac Dr., Tallahassee, FL 32310, USA \\ ${ }^{\circ}$ CNRS-UMR 7704, IPGP, 4 place Jussieu, 75005 Paris, France \\ ${ }^{\mathrm{d}}$ IMPMC-CNRS, 140 rue de Lourmel, 75015 Paris, France. \\ RECEIVED DATE (automatically inserted by publisher); massiot@cnrs-orleans.fr
}

High resolution solid state NMR has become an extremely useful tool for the structural characterization of a large variety of materials ranging from inorganic to porous materials, zeolites, hybrid organic-inorganic, organic and bio-involved materials. This is due to the ability of NMR to characterize ordered crystalline structures, but also to give detailed insight to the structure of partly disorganized, amorphous or glassy materials ${ }^{1,2}$. An important part of the power of solid state NMR methods comes from their ability to produce homo-nuclear or heteronuclear correlation charts that can evidence spatial proximity (from dipolar interaction) ${ }^{3,4}$ or chemical bonding (from Jcouplings) $)^{1,3}$, as used to derive protein structures in liquid state NMR experiments. Nevertheless a major difficulty arises with quadrupolar nuclei (nuclear spin $I>1 / 2$ ) because the quadrupolar interaction induces quick relaxation in liquid state, and broadening at first and second order in solids. The quadrupolar nuclei are the most abundant nuclei in inorganic materials and of crucial importance in many biological structures ${ }^{5}$. The question of efficiently generating a correlation between quadrupolar nuclei under high resolution conditions (fast Magic Angle Spinning MAS and high magnetic fields) remained an open question. In this contribution we show that such a correlation experiment can be generated with a simple and robust pulse sequence, using an isotropic (or scalar) interaction that does not necessitate reintroduction by sophisticated spin manipulation. We demonstrate the experiment with a $\left\{{ }^{17} \mathrm{O}\right\}{ }^{27} \mathrm{Al}$ (both $\mathrm{I}=5 / 2$ nuclei) experiment carried out on a crystalline test sample and show that the technique is reliable and sensitive enough to unambiguously evidence the presence of an unusual "tricluster" $\mu_{3}$ oxygen coordination in a glass of $\mathrm{CaAl}_{2} \mathrm{O}_{4}$ composition, with specific ${ }^{17} \mathrm{O}$ and ${ }^{27} \mathrm{Al}$ signatures.

Two possible ways exist for building up heteronuclear high resolution solid state NMR experiments. The first, and commonly used, method is to restore the through space dipolar interaction. This interaction vanishes under Magic Angle Spinning (MAS) and has to be reintroduced using continuous wave or modulated radio frequency (r.f.) pulses in a Cross Polarization (CPMAS) experiments. This is very efficient for pairs of $\mathrm{I}=1 / 2$ nuclei but suffers large limitations when involving a quadrupolar nucleus, because spin locking requires very small r.f. fields ${ }^{6,7}$. This leads to difficulties in obtaining homogeneous irradiation of the whole spectral domain which extends over typically tens of $\mathrm{kHz}$ (offset dependence). The CPMAS becomes even more complex, difficult and insensitive, when dealing with pairs of quadrupolar nuclei ${ }^{8}$. The second method makes use of the non-vanishing isotropic terms, namely the scalar (or isotropic) part of the indirect Jcoupling ${ }^{9}$. This interaction is directly characteristic of the existence of a chemical bound and can provide very detailed insight to the structure of crystalline or glassy materials ${ }^{1,3,10-13}$. Although small to very small (expected tens of $\mathrm{Hz}$ in our materials) as compared to the other interactions ( $\mathrm{kHz}$ to $\mathrm{MHz}$ ), the isotropic J-coupling terms do not vanish upon MAS and thus do not necessitate reintroduction. However, it requires long evolution times to develop and, consequently, could only be used for spin systems exhibiting long enough spin-spin relaxation times $\left(\mathrm{T}_{2}{ }^{\prime} \text { or coherence life time }\right)^{14}$. Finally it is important to remark that there exist, to our knowledge, few (if any) measurement of J-coupling between quadrupoles. In liquid state experiment the rapid reorientation induces quick relaxation that precludes their observation; while in solid state the dominant quadrupolar broadenings $(\sim \mathrm{kHz})$ masks these small effects $(\mathrm{Hz})$. This interaction thus remains largely unknown for the case of two quadrupoles but we think that we demonstrate that it is present and usable.

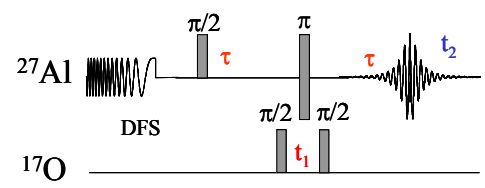

Figure 1 : HMQC pulse sequences. All pulses are Central Transition CT-selective, $\tau$ and $t_{1}$ are synchronized with MAS spinning rate.

The experiment that we propose is a slightly modified version of the Heteronuclear Multiple Quantum Correlation (HMQC figure 1) experiment that we previously used for ${ }^{27} \mathrm{Al} /{ }^{31} \mathrm{P}$ correlation ${ }^{13}$. It leads a spectrum correlating the directly observed ${ }^{27} \mathrm{Al}$ Central Transition (CT) spectrum with the indirectly observed ${ }^{17} \mathrm{O}$ CT spectrum. The robustness of the sequence comes from the minimum number of pulses involved on both channels, all pulses selectively exciting the central transitions in the approximation of fictitious $\mathrm{I}=1 / 2$ spins. This approach was previously used in several different experiments ${ }^{15,16,13}$, and keeps providing a broadband excitation of the whole spectrum of the central transitions, even at high fields. The HMQC experiment is run synchronized with the MAS spinning rate so that possible spinning sidebands sum up in the indirect dimension ${ }^{17}$. Our experiments were acquired at high principal field $\left(750 \mathrm{MHz}-\mathrm{B}_{0}\right.$ 17.6 T) which reduces second order quadrupolar broadenings and increases sensitivity ${ }^{18,5}$, with a gain proportional to $\mathrm{B}_{0}{ }^{2}$ for each dimension, and to $\mathrm{B}_{0}{ }^{4}$ for the correlation experiment. The signal to noise of the whole experiment is optimized by several signal enhancement methods : Double Frequency Sweep (DFS) $)^{19}$ on the starting nucleus (gain $>2.0$ ), acquisition and processing of the full echo ${ }^{15,16,13}$ (gain of $\sim \sqrt{2}$ ). If we assume that the scalar J-coupling is the active interaction, the double quantum filtered signal grows with $\operatorname{Sin}^{2}(\pi J \tau) /(S+1 / 2)$, and competes with the $T_{2}$ ' exponential decay. The $T_{2}$ ' of half integer quadrupolar nuclei can be significantly increased when spinning slightly off the magic angle $^{20}$. For our test sample (CA2), figure $2 \mathrm{a}$ shows that $\mathrm{T}_{2}$, gets nearly twice as long, with a signal enhancement of $\sim 3$, when running the HMQC experiment off the magic angle by $\sim 1^{\circ}$. Under 
these conditions, the dipolar interaction partially remains (off magic angle contribution) and may participate in the correlation. We can remark that this angle offset remains small enough to enhance the signal without broadening the lineshapes of both nuclei. Moreover, because both nuclei undergo second order broadening, the $\left\{{ }^{17} \mathrm{O}\right\}^{27} \mathrm{Al}$ correlation chart contains the encoding of their relative spatial orientation.

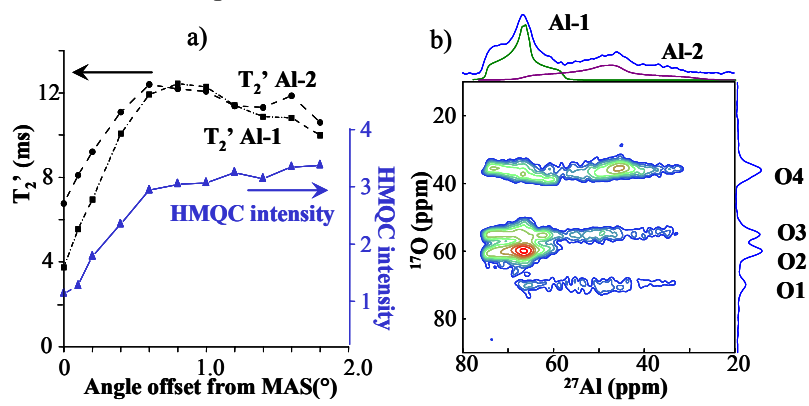

Figure 2: ${ }^{17} \mathrm{O} \quad 30 \%$ enriched $\mathrm{CA}_{2}-\mathrm{CaAl}_{2} \mathrm{O}_{7}$ crystalline sample: a) variation of $\mathrm{T}_{2}$, for the two $\mathrm{Al}$ sites and $\mathrm{HMQC}$ intensity (normalized to on angle) versus angle offset from MAS. b) $\left\{{ }^{17} \mathrm{O}\right\}^{27} \mathrm{Al}$ HMQC spectrum $\left(v_{\mathrm{R}} 15 \mathrm{kHz}, \tau 3 \mathrm{~ms}, 17.6 \mathrm{~T}-750 \mathrm{MHz}, 64 \mathrm{scans}\right)$.

The structure of Grossite $\left(\mathrm{CA} 2-\mathrm{CaAl}_{4} \mathrm{O}_{7}\right)$ crystalline phase involves 4 different ${ }^{17} \mathrm{O}$ sites ${ }^{22}$ : three with the usual $\mu_{2}$ coordination, $\mathrm{OAl}_{2}(\mathrm{O} 1, \mathrm{O} 2, \mathrm{O} 3)$ and one with a unique example, in a crystalline compound of that family, of a "tricluster" $\mu_{3}$ coordination: $\mathrm{OAl}_{3}(\mathrm{O} 4)$. Aluminum occupies two different $\mathrm{Al}\left(\mu_{2}\right)_{4-\mathrm{x}}\left(\mu_{3}\right)_{\mathrm{x}}$ sites : $\mathrm{Al}_{1}(\mathrm{x}=1)$ and $\mathrm{Al}_{2}(\mathrm{x}=2)$ with different ${ }^{27} \mathrm{Al}$ chemical shifts and quadrupolar couplings ${ }^{21}$. The connectivity scheme is unambiguously established from the $\left\{{ }^{17} \mathrm{O}\right\}^{27} \mathrm{Al} \mathrm{HMQC}$ correlation spectrum (figure $2 \mathrm{~b}$ ) : $\mathrm{Al}-1$ is connected with $\mathrm{O} 4, \mathrm{O} 3$ and $2 \mathrm{xO} 2$ whereas $\mathrm{Al}-2$ is connected with $2 \mathrm{xO} 4, \mathrm{O} 3$ and $\mathrm{O} 1$. Summarizing the NMR parameters of the $\mathrm{CA} 2$ and $\mathrm{CA}\left(\mathrm{CaAl}_{2} \mathrm{O}_{4}\right)$ crystals (supp. inf.) we remark that the ${ }^{27} \mathrm{Al}$ isotropic chemical shift of $\operatorname{Al}\left(\mu_{2}\right)_{4-\mathrm{x}}\left(\mu_{3}\right)_{\mathrm{x}}$ environment decreases by $5 \mathrm{ppm}$ per $\mathrm{x}$ or $\mu_{3}$, while ${ }^{17} \mathrm{O} \mu_{2}$ are found at $\sim 70 \mathrm{ppm}$ and $\mu_{3}$ at $\sim 40 \mathrm{ppm}$.

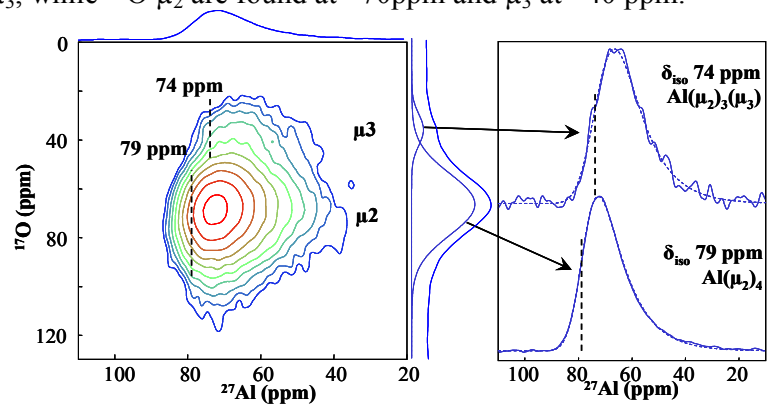

Figure $3:\left\{{ }^{17} \mathrm{O}\right\}^{27} \mathrm{Al}$ HMQC spectrum $\left(v_{\mathrm{R}} 25 \mathrm{kHz}, \tau 7 \mathrm{~ms}, \quad 17.6 \mathrm{~T}\right.$, 480 scans) of CA-glass $\left({ }^{17} \mathrm{O} 30 \%\right.$ enriched $)$ and ${ }^{27} \mathrm{Al}$-slices taken at $\mu_{2}$ and $\mu_{3}$ locations, exhibiting a $5 \mathrm{ppm}$ difference in the isotropic chemical shift. The doted lines are the modelled lines considering a GIM distribution ${ }^{2}$. The dashed lines indicate the position of ${ }^{27} \mathrm{Al}$ isotropic chemical shifts.

Given the robustness of the sequence, and its remarkable sensitivity (only 64 transients for the CA2 experiment), it was possible to acquire a spectrum of a ground droplet of $\sim 50 \mathrm{mg}$ of a CA $\left(\mathrm{CaO}-\mathrm{Al}_{2} \mathrm{O}_{3}\right)$ glass sample obtained with a contactless laser heated aerodynamic levitation device ${ }^{23}$. The ${ }^{17} \mathrm{O}$ and ${ }^{27} \mathrm{Al}$ individual MAS and MQMAS spectra of CA glass already provide information. The distribution of isotropic chemical shifts dominates the ${ }^{17} \mathrm{O}$ spectra with small second order effects ${ }^{24}$, they shows a main line extending from $\sim 90$ down to $\sim 30 \mathrm{ppm}$, clearly suggesting two Gaussian components at 69 and $37 \mathrm{ppm}$. This $37 \mathrm{ppm}$ component, absent in Ca rich CA38 glass $^{24}$, is located at the expected $\mu_{3}$ position. The distributions of both isotropic chemical shifts and quadrupolar interaction dominate the ${ }^{27} \mathrm{Al}$ dimension inducing typical asymmetric line shapes (with $\delta_{\text {iso }}$ in its rising left edge) that can be reliably modeled using a Gaussian Isotropic Model (GIM) ${ }^{2}$. The $\left\{{ }^{17} \mathrm{O}{ }^{27} \mathrm{Al}\right.$ HMQC correlation spectrum (figure 3 ) confirms the presence of two bridging oxygen components $\left(\mu_{2}\right.$ and $\left.\sim 5 \% \mu_{3}\right)$ with their relevant aluminum counterparts $\operatorname{Al}\left(\mu_{2}\right)_{4}$, and $\operatorname{Al}\left(\mu_{2}\right)_{3}\left(\mu_{3}\right)_{1}$ unambiguously identified from their isotropic chemical shifts (79 and $74 \mathrm{ppm})$. This result is the first comprehensive experimental proof of the presence of $\mu_{3}$ oxygen sites ${ }^{22,25-27}$, both from their $\mathrm{O}$ and $\mathrm{Al}$ signature.

In conclusion, we showed for the first time that it is possible to acquire efficiently heteronuclear correlation experiments in solid state between second order broadened half integer quadrupolar nuclei using isotropic mixing, presumably mediated by a scalar J-coupling that remains largely unknown. This experiment is possible thanks to the gain of sensitivity proportional to the fourth power of the principal field that turns a challenging experiment to a real efficient tool. This class of experiment could be extended to other pairs of nuclei. We believe that it may become very usefull, providing detailed insight to the structure and properties of glasses, porous or mesoporous framework materials, zeolites, hybrid organic-inorganic or even bio-involved materials, addressing questions like the characterization of oxygen protonation state or activity of catalytic materials

Acknowledgements : We acknowledge financial support from CNRS UPR4212, Région Centre, CNRS (CM) and "Le studium" fellowships (DI).

Supporting informations : Acquisition parameters, ${ }^{27} \mathrm{Al}$ and ${ }^{17} \mathrm{O}$ NMR parameters of the CA and CA2 crystals, and CA-glass.

Cadars, S.; Lesage, A.; Emsley L. J. Am. Chem. Soc. 2005, 127, 44664476

2 Neuville, D.R.; Cormier, L.; Massiot, D. Geochim. Cosmochim. Acta 2004, 68, 5071-5079

Hedin, N.; Graf, R.; Christiansen, S.C.; Gervais, C.; Hayward, R.C.; Eckert, J.; Chmelka, B.F. J. Am. Chem. Soc. 2004, $1249425-9432$ Brouwer, D.H.; Kristiansen, P.E.; Fyfe, C.A.; Levitt, M.H. J. Am. Chem. Soc. 2005, 127, 542-543

Wu, G.; Wong, A.; Gan, Z.; Davis, J.T.; J. Am. Chem. Soc. 2003, 125, 7182-7183

De Paul, S.M.; Ernst, M.; Shore, J.S.; Stebbins, J.F.; Pines, A. J. Phys. De Paul, S.M.; Ernst, M.; Shore,
Chem. B 1997, 101, 3240-3249

7 Eden, M.; Grins, J.; Shen, Z.; Weng, Z. J. Magn. Reson. 2004, 169, 279283

8 Eastman, M. J. Magn. Reson. 1999, 139, 98-108

9 Wasylishen, R. Encyclopedia of NMR, volume 9, 262-274 D.M. Grant and R.K. Harris editor, Wiley, New York, (2002).

10 Fyfe, C.A.; Grondey, H.; Feng, Y.; Kokotailo, G.T. J. Am. Chem. Soc. 1990, 112,8812-8820;

11 Fayon, F.; Le Saout, G.; Emsley, L.; Massiot, D. Chem. Commun. 2002, 1702-1703;

12 Fayon, F.; King, I.J.; Harris, R.K.; Gover, R.B.K.; Evans, J.S.O.; Massiot, D. Chem. Mater. 2003, 15, 2234-2239

13 Massiot, D.; Fayon, F.; Alonso, B.; Trebosc, J.; Amoureux, J.P. J. Magn. Reson. 2003, 164, 165-170

14 De Paepe, G.; Hodgkinson, P.; Emsley, L. Chem. Phys. Lett. 2003, 376, 259-267

15 Grandinetti, P.J; Baltisberger, J.H; Llor, A; Lee, Y.K.; Werner, U.; Eastman, M.A.; Pines, A. J. Magn. Reson. A 1993, 103, 72-81

16 Massiot, D.; Touzo, B.; Trumeau, D.; Coutures, J.P.; Virlet, J.; Florian, Massiot, D.; Touzo, B.; Trumeau, D.; Coutures, J.P.
P.; Grandinetti, P.J. Solid State NMR 1996, 6, 73-83

17 Massiot, D. J. Magn. Reson. A 1996, 122, 240-244

18 Gan, Z.; Gor'kov, P.; Cross, T.A.; Samoson, A.; Massiot, D. J. Am. Chem. Soc. 2002, 124, 5634-5635

19 Iuga, D.; Kentgens, A.P.M. J. Magn. Reson. 2002, 158, 65-72

20 Kwak, H.T.; Srinivasan, P.; Quine, J.; Massiot, D.; Gan, Z. Chem. Phys. Letters $2003,376,75-82$

21 Skibsted, J.; Henderson, E.; Jakobsen, H.J. Inorg. Chem. 1993, 32, 1013 1027

22 Stebbins, J.F.; Oglesby, J.V.; Kroeker, S. Am. Mineral. 2001, 86, $1307-$ 1311

23 Massiot, D.; Trumeau, D.; Touzo, B.; Farnan, I.; Rifflet, J.C.; Douy, A.; Coutures J.P.J. Phys. Chem. 1995, 99 16455-16459

24 Allwardt, J.R.; Keun Lee, S.; Stebbins, J.F. Am. Mineral. 2003, 88, 949954

25 Lacy, E.D. Phys. Chem. Glasses 1963, 4, 234-238

26 Stebbins, J.F.; Xu, Z. Nature 1997, 390, 60-61

27 Toplis, M.J.; Dingwell, D.B.; Lenci, T. Geochim. Cosmochim. Acta 1997, Toplis, M.J.; D 


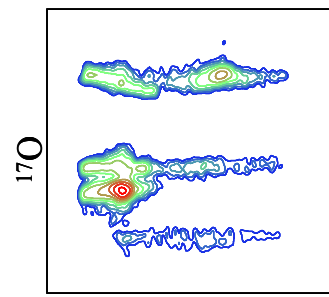

${ }^{27} \mathrm{Al}$ $\mu 3$

$\mu 2$

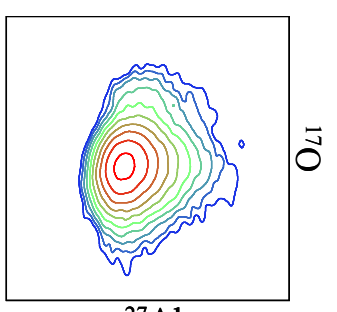

${ }^{27} \mathrm{Al}$

We show for the first time that it is possible to acquire high resolution heteronuclear NMR correlation experiments in solid state between second order broadened half integer quadrupolar nuclei (i.e. ${ }^{27} \mathrm{Al}$ and ${ }^{17} \mathrm{O}$ ) using the scalar J-coupling. The sensitivity of the experiment is dramatically improved at high fields (gain proportional to the fourth power of the principal field) with a combination of signal enhancement techniques. This turns a challenging experiment to a real tool. We apply this experiment to characterize a Calcium Aluminate glass in which we prove the presence of tricluster $\mu_{3}$ Oxygen sites and describe the signature of their directly bonded Aluminum sites. Applications involve a large range of possible pairs of quadrupolar nuclei in different materials like glasses, porous or mesoporous framework materials, zeolites, hybrid organic-inorganic, and bioinvolved materials. 